\title{
Intraoperative intracranial pressure monitoring in the pediatric craniosynostosis population
}

\author{
Brendan F. Judy, MD, ${ }^{1}$ Jordan W. Swanson, MD, ${ }^{2,3}$ Wuyang Yang, MD, ${ }^{4}$ Phillip B. Storm, MD, $, 1,5$ \\ Scott P. Bartlett, MD, ${ }^{2,3}$ Jesse A. Taylor, MD, ${ }^{2,3}$ Gregory G. Heuer, MD, PhD, ${ }^{1,5}$ and \\ Shih-Shan Lang, MD ${ }^{1,5}$
}

Divisions of ${ }^{1}$ Neurosurgery and ${ }^{3}$ Plastic and Reconstructive Surgery, Children's Hospital of Philadelphia; ${ }^{2}$ Division of Plastic Surgery, Department of Surgery, and ${ }^{5}$ Department of Neurosurgery, Perelman School of Medicine, University of Pennsylvania, Philadelphia, Pennsylvania; and ${ }^{4}$ Department of Neurosurgery, Johns Hopkins Hospital, Baltimore, Maryland

OBJECTIVE Evaluation of increased intracranial pressure (ICP) in the pediatric craniosynostosis population based solely on ophthalmological, clinical, and radiographic data is subjective, insensitive, and inconsistent. The aim of this study was to examine the intraoperative ICP before and after craniectomy in this patient population.

METHODS The authors measured the ICP before and after craniectomy using a subdural ICP monitor in 45 children. They regulated end-tidal carbon dioxide and the monitoring site under general anesthesia to record consistent ICP readings.

RESULTS The average age of the patient population was 29 months (range 3.8-180.5 months). Thirty-seven patients $(82.2 \%)$ were undergoing initial craniosynostosis procedures. All craniosynostosis procedures were categorized as one of the following: frontoorbital advancement $(n=24)$, frontoorbital advancement with distraction osteogenesis $(n=1)$, posterior vault distraction osteogenesis $(n=10)$, and posterior vault reconstruction $(n=10)$. Nineteen of 45 patients $(42.2 \%)$ had syndromic or multisuture craniosynostosis. The mean postcraniectomy ICP (8.8 mm Hg, range 2-18 mm Hg) was significantly lower than the precraniectomy ICP $(16.5 \mathrm{~mm} \mathrm{Hg}$, range $6-35 \mathrm{~mm} \mathrm{Hg})(p<0.001)$. Twenty-four patients (53\%) had elevated ICP prior to craniectomy, defined as $\geq 15 \mathrm{~mm} \mathrm{Hg}$. Only 4 (8.9\%) children had papilledema on preoperative funduscopic examination (sensitivity $17 \%$, specificity $100 \%$, negative predictive value $51 \%$, and positive predictive value $100 \%$ ). There were no significant differences in elevated precraniectomy ICP based on type of craniosynostosis (syndromic/multisuture or nonsyndromic) or age at the time of surgery. Patients undergoing initial surgery in the first 12 months of life were significantly less likely to have elevated precraniectomy ICP compared with patients older than 12 months $(26.3 \%$ vs $73.1 \%, p=0.005)$.

CONCLUSIONS In this study, the authors report the largest cohort of syndromic and nonsyndromic craniosynostosis patients $(n=45)$ who underwent precraniectomy and postcraniectomy ICP evaluation. A craniectomy or completed craniotomy cuts for distractors effectively reduced ICP in 43/45 patients. The authors' findings support the notion that papilledema on funduscopy is a highly specific, however poorly sensitive, indicator of increased ICP, and thus is not a reliable screening method. These findings indicate that even nonsyndromic patients with craniosynostosis are at risk for increased ICP. Furthermore, patients who present prior to 12 months of age appear less likely to have elevated ICP on presentation. Further studies with other noninvasive imaging of the retina may be useful as an adjunct tool for determining elevated ICP.

https://thejns.org/doi/abs/10.3171/2018.5.PEDS1876

KEYWORDS pediatric; craniosynostosis; intraoperative; intracranial pressure monitoring; craniofacial

$\mathrm{E}$ LEVATED intracranial pressure (ICP) is a well-recognized sequela in children with syndromic or multisuture craniosynostosis, with an estimated prevalence of $30 \%-40 \% \%^{5,6,15,21,23-26}$ and nonsyndromic (single-suture) craniosynostosis with a prevalence thought to be $15 \%-20 \% .^{6,19,20,25,27}$ Premature closure of the cranial sutures can lead to restricted brain growth. ${ }^{9,10}$ Cranial vault expansion surgery can reverse or help prevent elevated ICP, which gives the brain the optimal conditions under which to maximize its potential. ICP monitoring provides

ABBREVIATIONS DO = distraction osteogenesis; FOA = frontoorbital advancement; ICP = intracranial pressure; OCT = optical coherence tomography; PVDO = posterior vault DO; PVR = posterior vault reconstruction.

SUBMITTED February 3, 2018. ACCEPTED May 15, 2018.

INCLUDE WHEN CITING Published online August 3, 2018; DOI: 10.3171/2018.5.PEDS1876. 
objective measurements that can aid the surgeon in evaluation and treatment of craniosynostosis..$^{13,25,29}$

Although perioperative ICP monitoring has been reported before, ${ }^{29}$ in this study we report the largest cohort of craniosynostosis patients undergoing monitoring $(\mathrm{n}=$ 45), encompassing both syndromic and nonsyndromic populations at one of the largest craniofacial centers in the United States.

Understanding which patients with craniosynostosis are at risk for elevated ICP may help to direct the timing of surgical intervention. The measurement of ICP prior to surgical intervention as well as immediately after craniectomy establishes objective measures of pressure that may serve as a baseline should the patient re-present postoperatively with recurrent symptoms of increased ICP. The purpose of this study was to 1) evaluate the efficacy of craniectomy in reducing ICP acutely, 2) report the characteristics of elevated ICP in craniosynostosis patients, and 3) address the role of papilledema as a predictor of increased ICP.

\section{Methods}

Patients at the Children's Hospital of Philadelphia were prospectively included from the Craniofacial Surgery Clinic from September 2014 to January 2016. The patients were enrolled during the morning of surgery by a research coordinator who was blinded to the study. All patients with craniosynostosis - syndromic or multisuture and nonsyndromic-were enrolled by the same research coordinator. Any patient who did not undergo ICP monitoring had refusal of consent. Each patient was evaluated preoperatively by a pediatric ophthalmologist, and direct funduscopy was performed to assess for papilledema. Enrollment yielded 45 of $79(57 \%)$ patients undergoing craniectomy for craniosynostosis. Patients who received a minimally invasive strip craniectomy for sagittal craniosynostosis with springmediated cranioplasty were excluded. ${ }^{2}$ Written informed consent was obtained from all parents or guardians, and the institutional review board of Children's Hospital of Philadelphia approved all procedures.

The sample size was not determined a priori. This study was part of a larger study examining optical coherence tomography (OCT) for ICP measurement in craniosynostosis patients. ${ }^{22}$ The patients in this paper served as a subset group for the patients undergoing OCT measurement. The endpoint for patient accrual occurred when the principal investigator (J.W.S.) left the institution.

In order to measure ICP during craniosynostosis surgery, a systematic approach was followed. In all cases, inhaled anesthetic agents were used, and the same agents were continued throughout the surgery. The same anesthetic agents were used in all patients so as not to confound the ICP measurements. All craniosynostosis procedures were categorized as one of the following: frontoorbital advancement (FOA), FOA with distraction osteogenesis (DO), posterior vault reconstruction (PVR), or posterior vault DO (PVDO). Patients who underwent PVR or PVDO were positioned prone and horizontal to the floor. Patients who underwent FOA or FOA with DO were positioned supine. The head of the bed was maintained at a neutral position throughout the case. Prior to the planned craniectomy, the patient's end-tidal $\mathrm{CO}_{2}$ was normalized to $36 \mathrm{~mm} \mathrm{Hg}$, and an initial burr hole was placed as part of the planned craniectomy. Next, a small linear dural incision, $1-2 \mathrm{~mm}$ in length, was made. A flexible Camino ICP fiberoptic probe (Integra LifeSciences) was introduced through the durotomy and advanced $1-2 \mathrm{~cm}$ into the subdural space until an acceptable waveform was seen. The waveform was evaluated on the monitor and followed until the ICP value had stabilized for 1 minute, and that ICP measurement was recorded. The craniectomy or craniotomy cuts and planned craniosynostosis surgery were then completed. In order to decrease any potential continuous CSF leakage and undue influence on ICP, a piece of Gelfoam was placed on the 1- to 2-mm dural opening while performing the craniectomy. The craniectomy typically took less than 30 minutes to complete, and scant to no CSF leakage was observed clinically. Prior to closing, the Camino ICP probe was reinserted into the same subdural space and allowed to stabilize, and a second ICP measurement was recorded. Primary dural closure was then performed with single 4-0 Nurolon suture (Ethicon) immediately after ICP measurement. Most importantly, there were no continued CSF leaks postoperatively or hemorrhages on the postoperative head CT scans or clinical complications with ICP measurement.

Data are presented as the mean and range for continuous variables, and as frequency for categorical variables. Analysis was carried out using paired and unpaired t-tests for continuous variables. Chi-square and Fisher's exact tests were used for categorical data. The mean age at the time of the procedure was compared among the 4 cohorts using ANOVA; $\mathrm{p} \leq 0.05$ was considered statistically significant. Statistical analyses were performed using VassarStats (Vassar College).

\section{Results}

The mean age of the patient population at time of procedure was 29.4 months with a range of 3.8-180.5 months (Table 1). Thirty-seven patients $(82.2 \%)$ were undergoing their initial intracranial surgical procedure. Twenty-four patients underwent FOA, 1 patient underwent FOA with DO, 10 patients underwent PVR, and 10 patients underwent PVDO (Table 1). Nineteen of 45 patients (42.2\%) had

TABLE 1. Mean age at the time of the procedure of patients undergoing craniosynostosis surgery

\begin{tabular}{|c|c|c|c|}
\hline & $\begin{array}{c}\text { No. of } \\
\text { Patients (\%) }\end{array}$ & $\begin{array}{c}\text { Mean Age at } \\
\text { Procedure (mos) }\end{array}$ & $\begin{array}{c}\mathrm{p} \\
\text { Value }\end{array}$ \\
\hline Overall & $45(100)$ & 29.4 , range $3.8-180.5$ & \\
\hline Initial surgery & 37 (82.2) & 22.7 & \\
\hline Syndromic/multisuture & $19(42.2)$ & 41.9 & \multirow{2}{*}{0.09} \\
\hline Nonsyndromic & $26(57.8)$ & 20.2 & \\
\hline FOA & $24(53.3)$ & 30.5 & \multirow{4}{*}{0.51} \\
\hline FOA w/ DO & $1(2.2)$ & 3.8 & \\
\hline PVR & $10(22.2)$ & 17.2 & \\
\hline PVDO & $10(22.2)$ & 41.4 & \\
\hline
\end{tabular}


TABLE 2. Craniosynostosis classification

\begin{tabular}{lc}
\hline Craniosynostosis Classification & No. of Patients (\%) \\
\hline Overall & $45(100)$ \\
\hline Nonsyndromic & $26(57.8)$ \\
\hline Sagittal & $11(24.4)$ \\
\hline Metopic & $10(22.2)$ \\
\hline Coronal & $4(8.9)$ \\
\hline Lambdoid & $1(2.2)$ \\
\hline Syndromic/multisuture & $19(42.2)$ \\
\hline Apert & $4(8.9)$ \\
\hline Saethre-Chotzen & $4(8.9)$ \\
\hline Multisuture & $4(8.9)$ \\
\hline Crouzon & $2(4.4)$ \\
\hline Treacher-Collins & $1(2.2)$ \\
\hline Beckwith-Wiedemann & $1(2.2)$ \\
\hline 6p duplications & $1(2.2)$ \\
\hline Femoral hypoplasia-unusual facies & $1(2.2)$ \\
\hline Muenke & $1(2.2)$ \\
\hline
\end{tabular}

syndromic or multisuture nonsyndromic craniosynostosis (Table 1). There were no significant differences in mean age at the time of the procedure dependent on the type of surgery performed $(p=0.51)$ or between age at the time of the syndromic/multisuture or nonsyndromic procedure $(\mathrm{p}$ $=0.09)($ Table 1). Syndromic/multisuture craniosynostosis was further classified into the following: Apert $(n=4)$, Saethre-Chotzen $(n=4)$, multisuture $(n=4)$, Crouzon $(n=$ 2), Treacher-Collins $(n=1)$, Beckwith-Wiedemann $(n=1)$, $6 \mathrm{p}$ duplications $(\mathrm{n}=1)$, femoral hypoplasia-unusual facies $(n=1)$, and Muenke $(n=1)$ (Table 2). Overall, there were no significant differences between characteristics of the included patient cohort $(\mathrm{n}=45)$ and the eligible cohort $(\mathrm{n}$ $=34$ ) not included.

Forty-three of 45 patients demonstrated an acute decrease in ICP by at least $2 \mathrm{~mm} \mathrm{Hg}$, with a mean decrease of $7.7 \mathrm{~mm} \mathrm{Hg}$. Two patients, both of whom underwent FOA, had the same ICP pre- and postcraniectomy. The

\section{TABLE 3. Papilledema as a predictor of elevated ICP}

\begin{tabular}{lc}
\hline & Value \\
\hline No. of patients w/ papilledema & $4 / 45(8.9)$ \\
\hline Elevated precrani ICP & $24 / 45(53.3)$ \\
\hline Elevated precrani ICP w/ papilledema & $4 / 24(16.7)$ \\
\hline Elevated precrani ICP w/o papilledema & $20 / 24(83.3)$ \\
\hline Mean precrani ICP (range), $\mathrm{mm} \mathrm{Hg}^{*}$ & $16.5(6-36)$ \\
\hline Sensitivity, \% & 16.7 \\
\hline Specificity, \% & 100 \\
\hline NPV, $\%$ & 51.2 \\
\hline PPV, \% & 100 \\
\hline Mean postcrani ICP (range), $\mathrm{mm} \mathrm{Hg}^{*}$ & $8.8(2-18)$ \\
\hline
\end{tabular}

Precrani = precraniectomy; postcrani $=$ postcraniectomy .

* Statistically significant difference between pre- and postcraniectomy values.

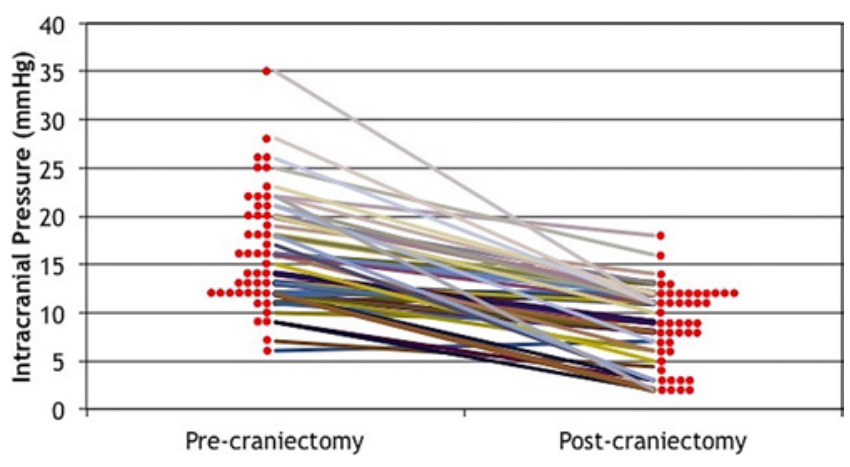

FIG. 1. Overall trend of ICP for all patients undergoing craniosynostosis surgery. Red circles represent individual patients. Figure is available in color online only.

mean postcraniectomy ICP was significantly lower than the mean precraniectomy ICP $(8.8$ vs $16.5 \mathrm{~mm} \mathrm{Hg}$, p < 0.0001 ; Table 3 and Fig. 1). Twenty-four patients (53\%) had elevated ICP, defined as ICP $\geq 15 \mathrm{~mm} \mathrm{Hg} ;{ }^{6-8,17,19,20}$ however, only $4(8.9 \%)$ patients had papilledema on funduscopic examination (Table 3). All 4 of the patients with papilledema on examination had elevated ICP (Table 3). Papilledema as a predictor of elevated ICP has high specificity (100\%) and positive predictive value $(100 \%)$ but low sensitivity (17\%) and negative predictive value (51.2\%) (Table 3).

When comparing the mean precraniectomy ICP, there was no significant difference between syndromic and nonsyndromic patients (17.68 vs $15.58 \mathrm{~mm} \mathrm{Hg}, \mathrm{p}=0.239$; Fig. $2)$. There was also no significant difference in precraniectomy ICP between the different surgical groups (FOA, FOA with DO, PVR, PVDO; $p=0.430$ ) (Fig. 2). In regard to postcraniectomy ICP, there was no significant difference between syndromic and nonsyndromic patients (8.68 vs $8.96 \mathrm{~mm} \mathrm{Hg}, \mathrm{p}=0.820$ ). Interestingly, there was a statistically significant difference in mean postcraniectomy ICP between patients undergoing FOA and PVR procedures (8.04 vs $11.1 \mathrm{~mm} \mathrm{Hg}, \mathrm{p}=0.038$ ) (Fig. 2), although these patients were not matched for age or diagnosis. There was

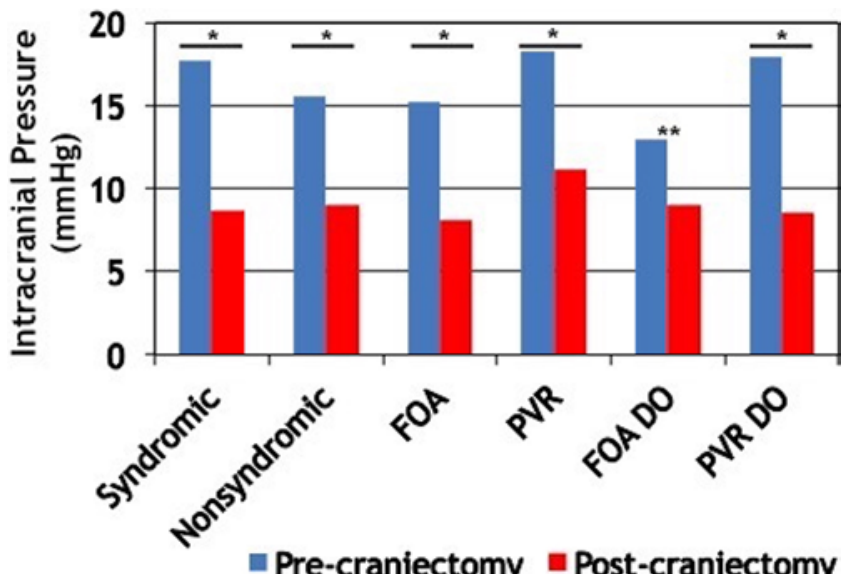

FIG. 2. Comparison of precraniectomy and postcraniectomy ICP between different procedures. ${ }^{*} p<0.01$. ${ }^{* *}$ Only 1 patient underwent FOA with DO; therefore, analysis is limited. Figure is available in color online only. 
TABLE 4. Analysis of precraniectomy elevated ICP

\begin{tabular}{lcc}
\hline & No. of Patients w/ Elevated ICP & p Value \\
\hline Overall & $24 / 45(53.3)$ & \\
\cline { 1 - 2 } Syndromic/multisuture & $13 / 19(68.4)$ & \multirow{2}{*}{0.15} \\
\cline { 1 - 2 } Nonsyndromic & $11 / 26(42.3)$ & \multirow{2}{*}{0.25} \\
\cline { 1 - 2 } Initial surgery & $18 / 37(48.6)$ & \\
\cline { 1 - 2 } Prior surgery & $6 / 8(75)$ & \\
\hline FOA & $11 / 24(45.8)$ & \\
\hline PVR & $6 / 10(60)$ & \\
\hline FOA w/ DO & $0 / 1(0)$ & \\
\cline { 1 - 2 } PVDO & $7 / 10(70)$ & \\
\cline { 1 - 2 }
\end{tabular}

no significant difference in postcraniectomy ICP between the other surgical groups or among the surgical groups as a whole $(\mathrm{p}=0.242)$. As one would predict, there was a statistically significant difference between mean precraniectomy and postcraniectomy ICP in syndromic patients, nonsyndromic patients, and patients undergoing FOA, PVR, and PVDO (Fig. 2). Comparison of precraniectomy to postcraniectomy ICP in the FOA with DO group is limited because only 1 patient underwent this procedure.

Of the 24 patients with elevated ICP prior to craniectomy, 13 had syndromic/multisuture craniosynostosis and 11 had nonsyndromic craniosynostosis; there was no significant difference in the percentage of patients with elevated precraniectomy ICP between these groups $(\mathrm{p}=0.15)$ (Table 4). Six of the patients with elevated precraniectomy ICP underwent prior surgery (Table 4). The average age of patients with elevated precraniectomy ICP was greater than that of patients without elevated ICP; however, this was not statistically significant (37.8 vs 19.8 months, $\mathrm{p}=$ 0.12).

Patients younger than 12 months showed lower rates of precraniectomy ICP elevation $(5 / 19,26.3 \%)$ than patients older than 12 months $(19 / 26,73.1 \%$; p $=0.005$ [Table 5]). This difference was consistent when an age cutoff of younger than 9 months was assessed, in which 2 of 11 (18.2\%) younger patients had elevated ICP compared with 22 of $34(64.7 \%)$ patients older than than 9 months $(\mathrm{p}=$ 0.019).

\section{Discussion}

Although neurocognitive impairment in patients with craniosynostosis may involve ICP, our understanding of ICP in this population remains limited. This study objectively evaluated acute changes in ICP following craniectomy in patients with craniosynostosis, with several notable findings. First, 43 of the 45 patients demonstrated a decrease in ICP of at least $2 \mathrm{~mm} \mathrm{Hg}$ from precraniectomy to postcraniectomy. Second, the ICP decrease was on average $7.7 \mathrm{~mm} \mathrm{Hg}$, representing a significant change among both nonsyndromic and syndromic patient cohorts. Third, the magnitude of ICP decrease did not appear to be related to the type of procedure or patient diagnosis in our cohort.

Conventional noninvasive methods (e.g., funduscopic examination, neuropsychiatric evaluation, bony changes on CT) for detecting increased ICP in pediatric cranio-
TABLE 5. Analysis of precraniectomy elevated ICP by age

\begin{tabular}{|c|c|c|}
\hline & $\begin{array}{l}\text { No. of Patients w/ } \\
\text { Elevated ICP (\%) }\end{array}$ & $\begin{array}{c}\mathrm{p} \\
\text { Value }\end{array}$ \\
\hline$<9$ mos w/ elevated ICP & 2/11 (18.2) & \multirow{2}{*}{0.019} \\
\hline$>9$ mos w/ elevated ICP & $22 / 34(64.7)$ & \\
\hline$<12$ mos w/ elevated ICP & $5 / 19(26.3)$ & \multirow{2}{*}{0.005} \\
\hline$>12$ mos w/ elevated ICP & 19/26 (73.1) & \\
\hline
\end{tabular}

synostosis patients often have equivocal results. Determining which patients have elevated ICP may help in deciding whether earlier intervention is needed in order to prevent cognitive and neurological dysfunction. Similar to previous reports, $1,4,14,16,18,28$ our study found that papilledema does not appear to accurately predict which patients will have elevated ICP. The relative young age at which craniosynostosis is often diagnosed may not allow for the progression of papilledema to be recognized on funduscopic examination. ${ }^{23,28,29}$ Tuite et al. ${ }^{28}$ hypothesized that papilledema in the young may be decreased due to the greater compliance of the unfused sutures, which may afford protection for the optic nerve from the effects of ICP. However, standard craniectomy with reconstruction or craniotomy cuts for distractors for craniosynostosis are both effective strategies for lowering ICP, as previously demonstrated..$^{20,21,23,29}$ In our study, there was a statistically significant difference between mean precraniectomy and postcraniectomy ICP (16.5 vs $8.8 \mathrm{~mm} \mathrm{Hg}, \mathrm{p}<0.0001)$, and this difference persisted in an analysis of the individual subgroups (syndromic, nonsyndromic, and the surgical groups). Therefore, we conclude that craniectomy with vault expansion appears to demonstrate an acute decrease in ICP. Whether this strategy holds true for a long-term decrease in chronically elevated ICP warrants further investigation.

We found no significant difference in precraniectomy ICP between the syndromic and nonsyndromic patients. Along the same lines, there was no significant difference in postcraniectomy ICP between the syndromic and nonsyndromic patients. In comparison of surgical groups, there was no significant difference in precraniectomy ICP among the groups. For postcraniectomy ICP, there was a significant difference between patients undergoing FOA and PVR procedures, suggesting that FOA may be more effective in initially lowering ICP. Additionally, we conclude that the type of craniosynostosis, syndromic/multisuture or nonsyndromic, did not correlate with the risk of elevated precraniectomy ICP. However, we did find that younger patients (assessed with age cutoffs of $<9$ months and $<12$ months) were significantly less likely to have elevated precraniectomy ICP. This suggests that there may be an advantage to treating younger children before elevated ICP develops. The normal variation of ICP with age is not well delineated. Although not statistically significant, Yokote et al. ${ }^{29}$ found a trend of ICP increasing with age. In contrast, Thompson et al. ${ }^{27}$ found a statistically significant inverse relationship between age and elevated ICP. Thompson theorized that "compensatory mechanisms" develop as children age. Interestingly, Renier et al. ${ }^{20}$ found 
that ICP had a linear relationship with age until 6 years of age, and thereafter ICP decreased. It is plausible that compensatory mechanisms do develop; however, the exact age at which these mechanisms emerge is unknown.

This study has limitations, including the potential influence of anesthesia, technique of ICP measurement, and the definition of elevated ICP in children. ICP measurements were taken under the influence of anesthesia both precraniectomy and postcraniectomy. The same halogenated anesthetic agent was used at each measurement interval with the same goal depth of sedation and expected corresponding agent concentration, thus not likely varying between the 2 measurement points in the case. ${ }^{11} \mathrm{Al}-$ though other factors such as an open incision may differ from ongoing (48-hour) ICP monitoring techniques, these were also consistent between precraniectomy and postcraniectomy measurements and would not be expected to cause internal confounding. Additionally, CSF leakage from the durotomy between measurements is a potential factor, mitigation of which was attempted with Gelfoam placement, and no significant drainage was observed clinically. However, in future studies, the durotomy could theoretically be repaired and sealed between measurements to better control for this factor, although this may also introduce added morbidity to the adjacent dura. This issue of accurately assessing ICP highlights the necessity of new technology to measure ICP noninvasively. ${ }^{22}$ Elevated ICP in this study was defined as $\geq 15 \mathrm{~mm} \mathrm{Hg}$ and was chosen due to the litany of prior studies that used this for the definition of elevated ICP. ${ }^{6-8,17,19,20}$ Given the recent study by Avery et al., ${ }^{3}$ which suggested that $20.6 \mathrm{~mm} \mathrm{Hg}(28$ $\mathrm{cm} \mathrm{H}_{2} \mathrm{O}$ ) is the 90th percentile of ICP in children, further investigation of this topic is warranted. Avery et al. did not evaluate children younger than 1 year, which clouds the relevance to our study in which we examined children as young as 3.8 months. Additionally, Avery et al. used lumbar puncture to evaluate ICP opening pressure, whereas a subdural monitor was used in this study.

\section{Conclusions}

We found that craniectomy uniformly and significantly decreases ICP acutely among patients with craniosynostosis who undergo cranial vault expansion. The clinical and long-term implications of this ICP decrease are not well understood; longitudinal follow-up will allow for further evaluation of potential recurrence of ICP and the possibility of associated neurocognitive impairment. As mentioned recently by Hayward et al., ${ }^{12}$ further data supporting specific ICP parameters in craniosynostosis are necessary to provide optimal patient care and guide our decision-making. We hope to utilize alternative noninvasive strategies, such as ocular coherence tomography (OCT), to assess for elevated ICP, which has already been used at our institution..$^{22}$ These new modalities will help the field further characterize the relationship between elevated ICP and neurocognitive impairment.

\section{Acknowledgments}

Research assistant support was provided in part by the Center for Human Appearance at the University of Pennsylvania.

\section{References}

1. Allen ED, Byrd SE, Darling CF, Tomita T, Wilczynski MA: The clinical and radiological evaluation of primary brain tumors in children, Part I: Clinical evaluation. J Natl Med Assoc 85:445-451, 1993

2. Arko L IV, Swanson JW, Fierst TM, Henn RE, Chang D, Storm PB, et al: Spring-mediated sagittal craniosynostosis treatment at the Children's Hospital of Philadelphia: technical notes and literature review. Neurosurg Focus 38(5):E7, 2015

3. Avery RA, Shah SS, Licht DJ, Seiden JA, Huh JW, Boswinkel J, et al: Reference range for cerebrospinal fluid opening pressure in children. N Engl J Med 363:891-893, 2010

4. Chou SY, Digre KB: Neuro-ophthalmic complications of raised intracranial pressure, hydrocephalus, and shunt malfunction. Neurosurg Clin N Am 10:587-608, 1999

5. Eide PK: The relationship between intracranial pressure and size of cerebral ventricles assessed by computed tomography. Acta Neurochir (Wien) 145:171-179, 2003

6. Eide PK, Helseth E, Due-Tønnessen B, Lundar T: Assessment of continuous intracranial pressure recordings in childhood craniosynostosis. Pediatr Neurosurg 37:310-320, 2002

7. Eide PK, Helseth E, Due-Tønnessen B, Lundar T: Changes in intracranial pressure after calvarial expansion surgery in children with slit ventricle syndrome. Pediatr Neurosurg 35:195-204, 2001

8. Gambardella G, Zaccone C, Cardia E, Tomasello F: Intracranial pressure monitoring in children: comparison of external ventricular device with the fiberoptic system. Childs Nerv Syst 9:470-473, 1993

9. Gault DT, Renier D, Marchac D, Ackland FM, Jones BM: Intracranial volume in children with craniosynostosis. $\mathbf{J}$ Craniofac Surg 1:1-3, 1990

10. Gault DT, Renier D, Marchac D, Jones BM: Intracranial pressure and intracranial volume in children with craniosynostosis. Plast Reconstr Surg 90:377-381, 1992

11. Greenberg MS: Neuroanesthesia, in Handbook of Neurosurgery, ed 7. New York: Thieme, 2010

12. Hayward R, Britto J, Dunaway D, Jeelani O: Connecting raised intracranial pressure and cognitive delay in craniosynostosis: many assumptions, little evidence. J Neurosurg Pediatr 18:242-250, 2016

13. Inagaki T, Kyutoku S, Seno T, Kawaguchi T, Yamahara T, Oshige $\mathrm{H}$, et al: The intracranial pressure of the patients with mild form of craniosynostosis. Childs Nerv Syst 23:14551459,2007

14. Lee HJ, Phi JH, Kim SK, Wang KC, Kim SJ: Papilledema in children with hydrocephalus: incidence and associated factors. J Neurosurg Pediatr 19:627-631, 2017

15. Liasis A, Thompson DA, Hayward R, Nischal KK: Sustained raised intracranial pressure implicated only by pattern reversal visual evoked potentials after cranial vault expansion surgery. Pediatr Neurosurg 39:75-80, 2003

16. Nazir S, O'Brien M, Qureshi NH, Slape L, Green TJ, Phillips $\mathrm{PH}$ : Sensitivity of papilledema as a sign of shunt failure in children. J AAPOS 13:63-66, 2009

17. Pople IK, Muhlbauer MS, Sanford RA, Kirk E: Results and complications of intracranial pressure monitoring in 303 children. Pediatr Neurosurg 23:64-67, 1995

18. Rangwala LM, Liu GT: Pediatric idiopathic intracranial hypertension. Surv Ophthalmol 52:597-617, 2007

19. Renier D: Intracranial pressure in craniosynostosis: pre-and postoperative recordings - correlation with functional results, in Persing JA, Edgerton MT, Jane JA (eds): Scientific Foundations and Surgical Treatment of Craniosynostosis. Baltimore: Williams \& Wilkins, 1989, pp 263-269

20. Renier D, Sainte-Rose C, Marchac D, Hirsch JF: Intracranial pressure in craniostenosis. J Neurosurg 57:370-377, 1982 
21. Siddiqi SN, Posnick JC, Buncic R, Humphreys RP, Hoffman HJ, Drake JM, et al: The detection and management of intracranial hypertension after initial suture release and decompression for craniofacial dysostosis syndromes. Neurosurgery 36:703-709, 1995

22. Swanson JW, Aleman TS, Xu W, Ying GS, Pan W, Liu GT, et al: Evaluation of optical coherence tomography to detect elevated intracranial pressure in children. JAMA Ophthalmol 135:320-328, 2017

23. Tamburrini G, Caldarelli M, Massimi L, Santini P, Di Rocco $\mathrm{C}$ : Intracranial pressure monitoring in children with single suture and complex craniosynostosis: a review. Childs Nerv Syst 21:913-921, 2005

24. Taylor WJ, Hayward RD, Lasjaunias P, Britto JA, Thompson $\mathrm{DN}$, Jones BM, et al: Enigma of raised intracranial pressure in patients with complex craniosynostosis: the role of abnormal intracranial venous drainage. J Neurosurg 94:377-385, 2001

25. Thompson DN, Harkness W, Jones B, Gonsalez S, Andar U, Hayward R: Subdural intracranial pressure monitoring in craniosynostosis: its role in surgical management. Childs Nerv Syst 11:269-275, 1995

26. Thompson DN, Harkness W, Jones BM, Hayward RD: Aetiology of herniation of the hindbrain in craniosynostosis. An investigation incorporating intracranial pressure monitoring and magnetic resonance imaging. Pediatr Neurosurg 26:288-295, 1997

27. Thompson DN, Malcolm GP, Jones BM, Harkness WJ, Hayward RD: Intracranial pressure in single-suture craniosynostosis. Pediatr Neurosurg 22:235-240, 1995

28. Tuite GF, Chong WK, Evanson J, Narita A, Taylor D, Hark- ness WF, et al: The effectiveness of papilledema as an indicator of raised intracranial pressure in children with craniosynostosis. Neurosurgery 38:272-278, 1996

29. Yokote A, Aihara Y, Eguchi S, Okada Y: Intraoperative preand post-craniofacial reconstruction intracranial pressure (ICP) monitoring in children with craniosynostosis. Childs Nerv Syst 29:1363-1367, 2013

\section{Disclosures}

The authors report no conflict of interest concerning the materials or methods used in this study or the findings specified in this paper.

\section{Author Contributions}

Conception and design: Lang, Swanson, Storm, Taylor, Heuer. Acquisition of data: Lang, Judy, Swanson. Analysis and interpretation of data: Lang, Judy, Swanson, Yang, Taylor, Heuer. Drafting the article: Lang, Judy. Critically revising the article: Lang, Judy, Swanson, Yang, Storm, Bartlett, Taylor. Reviewed submitted version of manuscript: all authors. Approved the final version of the manuscript on behalf of all authors: Lang. Statistical analysis: Lang, Judy, Swanson, Yang. Administrative/technical/material support: Lang. Study supervision: Lang.

\section{Correspondence}

Shih-Shan Lang: University of Pennsylvania Perelman School of Medicine, Philadelphia, PA. chens4@email.chop.edu. 